\title{
Root Canal Morphology of Mandibular Incisors Using Cone-Beam Computed Tomography in Two Population Samples: A Cross-Sectional Study
}

\author{
Martínez I', Torres $A^{2,3}$, J acobs $R^{3,4}$, Lepe $A^{1}$, J ara \\ $D^{1}$, Ramírez V' ${ }^{1}$, Concha $G^{1}$, Briner $A^{5}$ and Brizuela \\ $\mathrm{C}^{1 *}$ \\ ${ }^{1}$ Department of Endodontics, University of the Andes, \\ Chile \\ ${ }^{2}$ Department of Oral Health Sciences, University \\ Hospitals Leuven, Belgium \\ 3Department of Imaging and Pathology, KU Leuven, \\ Belgium \\ ${ }^{4}$ Department of Dental Medicine, Karolinska Institutet \\ Stockholm, Sweden \\ 5IMAX Centre of Radiology, Chile \\ *Corresponding author: Brizuela C, Department of \\ Endodontics, Universidad de los Andes, Mons, Álvaro del \\ Portillo 12.455,7620001 Las Condes, Santiago, Chile
}

Received: October 12, 2018; Accepted: November 12, 2018; Published: November 19, 2018

\begin{abstract}
Objective: To describe root canal morphology of mandibular incisors and their variability in Chilean and Belgian samples, using Cone-Beam Computed Tomography (СВCT).

Methods: A total of 698 mandibular incisors (353 from Chile and 345 from Belgium) were examined using СВCT images. The anatomical parameters analyzed were number of roots and canals, root canal configuration, presence of septum, tooth length, and radicular length. A descriptive analysis was performed. Differences between the two populations were explored using a generalized estimating equation for quantitative variables. A multilevel regression model was developed for nominal variables.
\end{abstract}

Results: The mandibular central incisor from both samples presented one root, as did the mandibular lateral incisor. One canal was present in most cases for both the mandibular central incisor and the lateral incisor. A type I root canal configuration was also predominant for the central incisor and the lateral incisor. The apical curvature was towards the vestibular direction in most cases, for both samples. A septum was present in $22 \%$ of Chilean central incisors and $33 \%$ of Belgian central incisors; for the lateral incisors the prevalence of a septum was $21 \%$ for the Chilean sample and 38\% for the Belgian sample.

Conclusion: The anatomical parameters analyzed for the mandibular incisors in Chilean and Belgian samples had statistical differences. The proposed septum classification could be useful for future investigations to determine the length at which a practitioner could expect to find such anatomical variations.

Keywords: Anatomy; Cone-beam computed tomography; Dental pulp cavity; Incisor; Root canal

\section{Introduction}

Locating, cleaning and shaping the root canal system may be challenging [1]. Knowledge of its complexity is essential in order to understand the principles and problems of conformation [1]. Furthermore, this understanding may aid the comprehension of the cleaning process, and the determination of the apical limit and the dimensions of the instrumentation [1-6]. It has been established that one of the causes of failure of endodontic therapy is incomplete treatment, which leaves canals untreated [1]. Therefore, an understanding and knowledge of root canal anatomy is vital to ensuring thorough root canal treatment.

In earlier studies, the root canal anatomy of the mandibular incisor has been described as simple, with no associated complexities [7-9]. However, numerous studies have revealed the existence of variations in the root canal morphology, such as a second canal, an apical delta, the presence of a septum and bifurcations, among others $[2,10-12]$. These variations may be related to variables such as race, age, and gender $[9,13]$.

Many studies have revealed variations in morphology among individuals of Asian race. A smaller amount of studies have analyzed

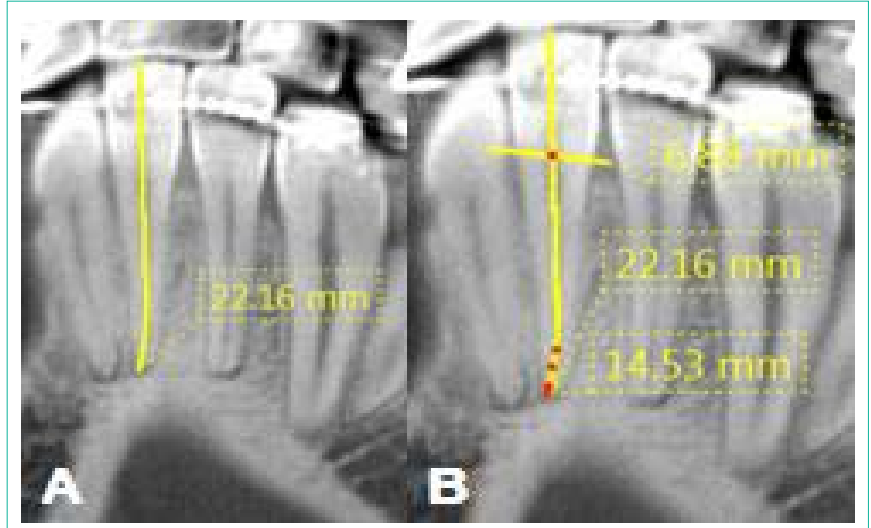

Figure 1: CBCT images of a mandibular incisor.

A Tooth length measured from the incisal border to the root apex. B Root length measured from the cement-enamel junction (represented by the horizontal line) to the root apex.

African, Latin-American and Caucasian patients, but these also show morphological variations $[14,15]$.

The techniques of clearing and staining, tooth extraction,
Austin J Radiol - Volume 5 Issue 2 - 2018

ISSN : 2473-0637 | www.austinpublishing group.com

Brizuela et al. (C) All rights are reserved
Citation: Martínez I, Torres A, Jacobs R, Lepe A, Jara D, Ramírez V, et al. Root Canal Morphology of Mandibular Incisors Using Cone-Beam Computed Tomography in Two Population Samples: A Cross-Sectional Study. Austin J Radiol. 2018; 5(2): 1083. 


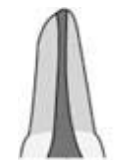

Type I

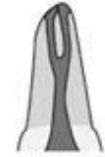

Type V

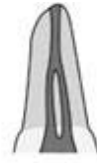

Type II

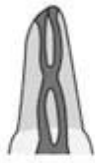

Type VI

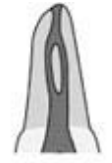

Type III

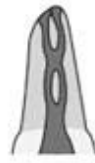

Type VII

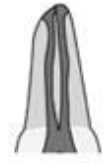

Type IV

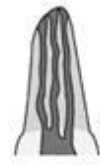

Type VIII

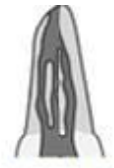

Type IX

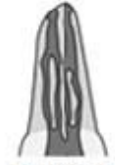

Type XI

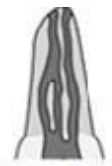

Type XII

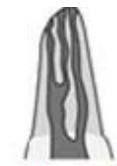

Type XIII

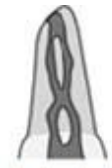

Type X

Figure 2: Vertucci's classification and Gulabivala's classification of root canal morphology.

Type I: a single canal extends from the pulp chamber to the apex. Type II: two separate canals leave the pulp chamber and join short of the apex to form one canal. Type III: one canal leaves the pulp chamber, divides into two within the root, and then merges to exit as one canal. Type IV: two separate and distinct canals extend from the pulp chamber to the apex. Type $\mathrm{V}$ : one canal leaves the pulp chamber and divides short of the apex into two separate and distinct canals with separate apical foramina. Type VI: two separate canals leave the pulp chamber, merge in the body of the root, and re-divide short of the apex to exit as two distinct canals. Type VII: one canal leaves the pulp chamber, divides and then rejoins within the body of the root, and finally re-divides into two distinct canals short of the apex. Type VIII: three separate and distinct canals extend from the pulp chamber to the apex. Type IX: three separate canals leave the pulp chamber and join short of the apex to form one canal. Type X: two separate canals leave the pulp chamber, unite and then divide into two within the body of the root, and finally join short of the apex to form one canal. Type XI: four canals leave the pulp chamber; both pairs unite within the root and emerge as two separate canals. Type XII: three canals leave the pulp chamber, two of them unite within the root, and finally they emerge as two separate canals. Type XIII: two canals leave the pulp chamber, one of them divides within the root and they emerge as three separate canals. Type XIV: four canals extend from the pulp chamber to the apex. Type XV: five canals leave the pulp chamber; two of them join within the root, and finally they emerge as four separate canals.

Table 1: Descriptive analysis of nominal variables for mandibular central and lateral incisors, by population.

\begin{tabular}{|c|c|c|c|c|c|c|c|c|}
\hline & \multicolumn{4}{|c|}{ Mandibular central incisor } & \multicolumn{4}{|c|}{ Mandibular lateral incisor } \\
\hline & \multicolumn{2}{|c|}{ Belgium } & \multicolumn{2}{|c|}{ Chile } & \multicolumn{2}{|c|}{ Belgium } & \multicolumn{2}{|c|}{ Chile } \\
\hline & $\mathrm{N}$ & $\%$ & $\mathrm{~N}$ & $\%$ & $\mathrm{~N}$ & $\%$ & $\mathrm{~N}$ & $\%$ \\
\hline \multicolumn{9}{|c|}{ Number of roots } \\
\hline 1 & 174 & 100 & 171 & 100 & 170 & 99.42 & 182 & 100 \\
\hline 2 & 0 & 0 & 0 & 0 & 1 & 0.58 & 0 & 0 \\
\hline \multicolumn{9}{|c|}{ Number of canals } \\
\hline 1 & 107 & 61.49 & 134 & 78.36 & 102 & 59.65 & 144 & 79.12 \\
\hline 2 & 67 & 38.51 & 37 & 21.64 & 69 & 40.35 & 38 & 20.88 \\
\hline \multicolumn{9}{|c|}{ Root canal configuration } \\
\hline Type I & 107 & 61.49 & 133 & 77.78 & 102 & 59.65 & 144 & 79.12 \\
\hline Type II & 1 & 0.58 & 5 & 2.92 & 1 & 0.58 & 2 & 1.1 \\
\hline Type V & 7 & 4.02 & 0 & 0 & 3 & 1.75 & 0 & 0 \\
\hline Type VI & 1 & 0.58 & 0 & 0 & 0 & 0 & 0 & 0 \\
\hline Type X & 2 & 1.15 & 0 & 0 & 1 & 0.58 & 0 & 0 \\
\hline \multicolumn{9}{|l|}{ Isthmus } \\
\hline Absent & 116 & 66.67 & 134 & 78.36 & 106 & 61.97 & 143 & 78.57 \\
\hline Type I & 25 & 14.36 & 24 & 14.04 & 21 & 12.28 & 31 & 17.03 \\
\hline Type II & 33 & 18.97 & 11 & 7.6 & 44 & 25.73 & 8 & 4.4 \\
\hline \multicolumn{9}{|c|}{ Curvature in the apical third of the canal } \\
\hline Buccal & 130 & 78.31 & 137 & 82.04 & 108 & 64.29 & 122 & 69.71 \\
\hline Straight & 34 & 20.48 & 29 & 17.37 & 56 & 33.33 & 52 & 29.71 \\
\hline Lingual & 2 & 1.21 & 1 & 0.59 & 4 & 2.38 & 1 & 0.58 \\
\hline
\end{tabular}

observation of sectioned cuts, and radiographic evaluation have been used in studies evaluating the root canal morphology of mandibular incisors [2,16-18]. However, Cone-Beam Computed Tomography (CBTC) has been used to evaluate the anatomy of the root canal system $[19,20]$ because it delivers high-resolution three-dimensional images in vivo [21] and, in comparison with micro CT scans, which provides precise quantitative and qualitative measurements of anatomical details, has a lower cost, requires less working time and 
can be applicable to larger sample, without being necessary to extract the tooth [12].

This research team is focused on characterizing the complexity and variability of root canal morphology of teeth in different populations as such to help creating clinical guidance notes assisting endodontists. Previously, a similar exercise had been done with regard to mandibular molars and mandibular premolars [22,23].

The purpose of this study was to describe root canal morphology of mandibular incisors and their variability in Chilean and Belgian samples, using $\mathrm{CBCT}$, and to provide important information about the complexity of the root canal morphology to clinicians.

\section{Materials and Methods}

A cross-sectional study was conducted. All images analyzed were obtained from digital files. The methodology used was the same as previous studies in mandibular molars and mandibular premolars $[22,23]$.

\section{Patients}

CBCT images were obtained from a non-probabilistic intentional sample from the database of a private dentomaxillo facial radiology practice in Santiago, Chile and from the database of the Dentomaxillo facial Imaging Center of the University Hospitals in Leuven, Belgium, between February 2011 and July 2013. The decision to undertake CBCT was made by the treating dentist as part of the dental treatment, with justifications such as preoperative implant planning, impacted mandibular third molars, complex periapical region and periodontal pathology, among others.

Ethical approval was obtained to carry out this study at the Leuven University Hospital (folio S57587), and an informed consent was obtained from the patients attending the hospital. For patients evaluated at the private dentomaxillo facial radiology practice in Santiago, Chile, authorization to use the information in the database for research purposes was obtained from the director of the center and ethical approval was obtained to carry out this study at the Universidad de los Andes, Santiago (folio CEC201756). All image data sets were anonymized to keep the identity of the patients confidential.

The following inclusion criteria were used: (1) the patient must present at least one mandibular incisor, either central incisor or lateral incisor; (2) the tooth to be evaluated should not present caries, nor occlusal or proximal restorations; (3) the tooth to be evaluated should not have had endodontic treatment; (4) the tooth to be evaluated must present apical closure compatible with complete root formation (Nolla stage 10) [24]; (5) absence of periapical lesions or periodontal ligament widening; (6) absence of radicular resorptions; (7) absence of root cysts or tumor lesions; (8) the patient must not have a condition that affects the normal development of teeth; and (9) a high-quality CBTC image must be available.

A random sample size was determined. The sample was selected by simple random sampling.

A total of 698 mandibular incisors (353 Chilean and 345 Belgian samples) from 220 patients (126 Chileans and 94 Belgians) met the required criteria and were analyzed.

\section{Radiographic technique}

The CBCT images were obtained using a 3D Accuitomo $170^{\circ}$ Tomograph (Morita, Kyoto, Japan) operating at $90 \mathrm{kV}$ and $8 \mathrm{~mA}$, with different Fields of View (FOV), according to the needs of the case, ranging from $40 \times 40 \mathrm{~mm}$ to $80 \times 80 \mathrm{~mm}$. The voxel size was $0.125 \mathrm{~mm}$. All CBCT exposures were made with a low radiation dose by a trained medical imaging technologist and were reviewed by a specialist in oral and maxillofacial radiology.

\section{Image analysis}

All CBCT scans were analyzed using "i-Dixel One Volume Viewer" (version 2.0.0, Morita, Kyoto, Japan) under standardized

Table 2: Descriptive analysis of quantitative variables for mandibular central and lateral incisors, by population (IS: Intercanal Septum; IB: Incisal Border; CRL: Coronoradicular Limit; AF: Apical Foramen).

\begin{tabular}{|c|c|c|c|c|c|c|c|c|c|c|}
\hline & \multicolumn{5}{|c|}{ Mandibular central incisor } & \multicolumn{5}{|c|}{ Mandibular lateral incisor } \\
\hline & $\mathrm{N}$ & $\operatorname{Mean}(\mathrm{mm})$ & SD & $\operatorname{Min}(\mathrm{mm})$ & $\operatorname{Max}(\mathrm{mm})$ & $\mathrm{N}$ & $\operatorname{Mean}(\mathrm{mm})$ & SD & $\operatorname{Min}(\mathrm{mm})$ & $\operatorname{Max}(\mathrm{mm})$ \\
\hline \multicolumn{11}{|l|}{ Tooth length } \\
\hline Belgium & 174 & 20.9 & 1.5 & 17.3 & 25 & 171 & 22.5 & 1.6 & 18.4 & 26.3 \\
\hline Chile & 171 & 20.3 & 1.8 & 16 & 24.7 & 184 & 21.9 & 1.8 & 18.8 & 27.3 \\
\hline \multicolumn{11}{|l|}{ Root length } \\
\hline Belgium & 174 & 12.9 & 1.3 & 9.8 & 16.6 & 171 & 14.1 & 1.4 & 10.3 & 17.8 \\
\hline Chile & 171 & 13.5 & 1.3 & 10.1 & 16.6 & 184 & 14.7 & 1.4 & 11.3 & 19.1 \\
\hline \multicolumn{11}{|l|}{ IS to IB } \\
\hline Belgium & 25 & 11.8 & 1.3 & 8.2 & 13.8 & 21 & 12.3 & 1 & 10.4 & 14.4 \\
\hline Chile & 24 & 11.7 & 2 & 8.1 & 14.7 & 31 & 11.7 & 1.8 & 14.2 & 6.5 \\
\hline \multicolumn{11}{|l|}{ IS to CRL } \\
\hline Belgium & 25 & 3.5 & 1.1 & 0 & 4.9 & 21 & 3.9 & 0.8 & 2.7 & 5.4 \\
\hline Chile & 24 & 3.2 & 1.2 & 0.9 & 4.9 & 31 & 3.3 & 1.1 & 0 & 4.9 \\
\hline \multicolumn{11}{|l|}{ IS to AF } \\
\hline Belgium & 25 & 3.5 & 1.5 & 1.3 & 8.3 & 21 & 4.4 & 1.6 & 1.4 & 7.2 \\
\hline Chile & 24 & 4.1 & 1.2 & 2.1 & 6 & 31 & 4.1 & 1.4 & 1.1 & 6.7 \\
\hline
\end{tabular}


Table 3: Comparative analysis of nominal variables for the mandibular central and latetal incisor, by country of origin and gender (multilevel regression model).

\begin{tabular}{|c|c|c|c|c|c|c|c|c|c|}
\hline & \multicolumn{3}{|c|}{ Number of canals } & \multicolumn{3}{|c|}{ Presence of septum } & \multicolumn{3}{|c|}{ Type of septum } \\
\hline & Odds Ratio & $\begin{array}{c}\text { Confidence interval } \\
95 \%\end{array}$ & $p$ value & Odds Ratio & $\begin{array}{l}\text { Confidence Interval } \\
95 \%\end{array}$ & $p$ value & Odds Ratio & $\begin{array}{l}\text { Confidence Interval } \\
95 \%\end{array}$ & $p$ value \\
\hline \multicolumn{10}{|c|}{ Central incisor } \\
\hline $\begin{array}{l}\text { Country of } \\
\text { origin }\end{array}$ & 2.27 & $1.41-3.65$ & $0.001^{*}$ & 1.81 & $1.12-2.93$ & $0.02^{*}$ & 2.43 & $1.03-5.74$ & $0.04^{*}$ \\
\hline \multicolumn{10}{|l|}{ Gender } \\
\hline Belgium & 1.84 & $0.99-3.44$ & $0.05^{\star}$ & 1.69 & $0.89-3.23$ & 0.11 & 0.64 & $0.21-1.91$ & 0.42 \\
\hline Chile & 0.99 & $0.47-2.10$ & 0.98 & 0.99 & $0.47-2.10$ & 0.98 & 0.35 & $0.08-1.65$ & 0.19 \\
\hline \multicolumn{10}{|c|}{ Lateral incisor } \\
\hline $\begin{array}{l}\text { Country of } \\
\text { origin }\end{array}$ & 2.6 & $1.62-4.16$ & $<0.0001^{*}$ & 2.28 & $1.42-3.65$ & $0.001^{*}$ & 8.12 & $3.17-20.78$ & $<0.001^{*}$ \\
\hline \multicolumn{10}{|l|}{ Gender } \\
\hline Belgium & 1.58 & $0.85-2.94$ & 0.17 & 1.62 & $0.86-3.03$ & 0.13 & 1.59 & $0.55-4.60$ & 0.39 \\
\hline Chile & 1.38 & $0.92--3.92$ & 0.08 & 2.04 & $0.99-4.20$ & $0.05^{\star}$ & 0.27 & $0.04-0.92$ & 0.15 \\
\hline
\end{tabular}

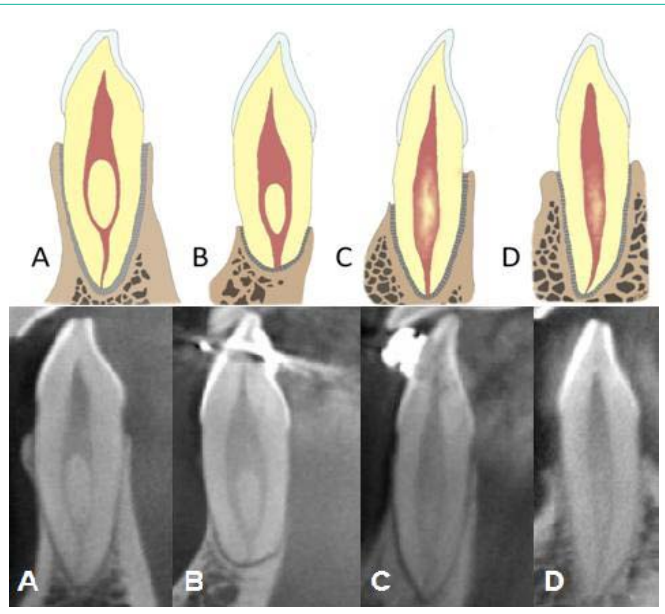

Figure 3: Types of septum in mandibular incisors.

A and B Type I: septum with oval shape, defined and clear limits, measurements can be made. C and D Type II: septum with elongated shape and undefined limits, for which no measurements can be made because it is difficult to establish stable references.

conditions, in a quiet and dimmed room with a diagnostic display (Barco MDRC-2120, Barco, Kortrijk, Belgium). Axial, coronal, and saggital two-dimensional sections were displayed on the monitor and the complete data set was evaluated. When necessary, the contrast and brightness of the image were adjusted using the program's image processing tool to ensure optimal viewing.

Images from the Chilean sample were evaluated by a postgraduate endodontic student from Universidad de los Andes, who had been previously calibrated with another postgraduate endodontic student from the Katholieke Universiteit Leuven, who in turn analyzed the images from the Belgian sample. The Kappa index was used. Concordance between the observers was measured (variables were categorized into intervals with mutually exclusive categories). Cohen's Kappa coefficient for interobserver and intraobserver agreement was 0.89 .

Population, sex, age and type of teeth were recorded (31: left mandibular first incisor, 32: left mandibular second incisor, 41: right mandibular first incisor, 42: right mandibular second incisor).
For all mandibular incisors, the observations included: (1) tooth length (Figure 1), (2) radicular length (Figure 1), (3) number of roots, (4) number of canals, (5) root canal configuration according to Vertucci's classificationand Gulabivala classification (Figure 2) [25,26], (6) apical curvature, (7) type of septum (Figure 3), and (8) relationship of the septum to different anatomical structures (Figure 4).

A descriptive analysis was performed for all variables. For quantitative variables (age, root length, bifurcation and unification of the canals), the mean, Standard Deviation (SD) and range were reported. Nominal variables (country of origin, evaluated incisor, number of roots, number of canals, root canal configuration, and type of septum) were tabulated according to absolute frequencies and percentages.

Differences between the two populations were explored using a generalized estimating equation for quantitative variables and a multilevel regression model for nominal variables, with a p-value of 0.05 or lower. The analysis was performed using Stata v14 software (Stata Corp, Texas, USA).

\section{Prevention of bias}

To prevent bias, different measures were applied such as simple random sampling, calibration of the evaluators, the same instrument of measurement, management of the environmental variables that could affect imaging analysis, registration of the gender and age of the patients, strict selection criteria and compliance with ethical standards, approval of the ethics committee, obtaining informed consent, and declaration of no conflict of interest.

\section{Results}

A total of 220 CBCT scans were analyzed. In the Belgian sample, consisting of 94 patients with a total of 345 mandibular incisors (174 first mandibular incisors and 171 second mandibular incisors), 55\% of the patients were female and $45 \%$ male. In the Chilean sample, of 126 patients with a total of 353 mandibular incisors (171 mandibular central incisors and 182 mandibular lateral incisors), 36\% of the patients were female and $64 \%$ were male. The nominal variables are shown in Table 1. The quantitative variables are shown in Table 2. There were also significant differences between the groups in the 
Table 4: Comparative analysis of quantitative variables for the mandibular central and lateral incisor, by country of origin, gender and age (generalized estimating equation).

\begin{tabular}{|c|c|c|c|c|c|c|c|c|c|c|c|c|c|c|c|}
\hline & \multicolumn{3}{|c|}{ Tooth length } & \multicolumn{3}{|c|}{ Root length } & \multicolumn{3}{|c|}{ IS to IB } & \multicolumn{3}{|c|}{ IS to CRL } & \multicolumn{3}{|c|}{ IS to AF } \\
\hline & $\begin{array}{l}\text { Coef } \\
(\mathrm{mm})\end{array}$ & $\begin{array}{c}\text { Confidence } \\
\text { interval 95\% }\end{array}$ & $p$ value & $\begin{array}{l}\text { Coef } \\
(\mathrm{mm})\end{array}$ & $\begin{array}{c}\text { Confidence } \\
\text { interval 95\% }\end{array}$ & $p$ value & $\begin{array}{l}\text { Coef } \\
(\mathrm{mm})\end{array}$ & $\begin{array}{c}\text { Confidence } \\
\text { interval 95\% }\end{array}$ & $p$ value & $\begin{array}{l}\text { Coef } \\
(\mathrm{mm})\end{array}$ & $\begin{array}{c}\text { Confidence } \\
\text { interval 95\% }\end{array}$ & $p$ value & $\begin{array}{l}\text { Coef } \\
(\mathrm{mm})\end{array}$ & $\begin{array}{c}\text { Confidence } \\
\text { interval 95\% }\end{array}$ & $p$ value \\
\hline \multicolumn{16}{|l|}{$\begin{array}{l}\text { Central } \\
\text { incisor }\end{array}$} \\
\hline $\begin{array}{l}\text { Country } \\
\text { of origin }\end{array}$ & 0.6 & $0.2-1.1$ & $0.007^{\star}$ & $(-) 0.6$ & $(-) 1.0-(-) 0.3$ & $0.001^{*}$ & 0.1 & $(-) 1.1-1.3$ & 0.84 & 0.3 & $(-) 0.4-1.1$ & 0.42 & $(-) 0.6$ & $(-) 1.4-0.3$ & 0.21 \\
\hline \multicolumn{16}{|l|}{ Gender } \\
\hline Belgium & 0.9 & $0.3-1.5$ & $0.002^{*}$ & 0.8 & $0.3-1.3$ & $0.001^{*}$ & 0.6 & $(-) 0.4-1.6$ & 0.26 & 0.3 & $(-) 0.5-1.1$ & 0.51 & $(-) 0.8$ & $(-) 2.0-0.3$ & 0.16 \\
\hline Chile & 1.0 & $0.4-1.7$ & $0.003^{*}$ & 0.9 & $0.4-1.4$ & $<0.001^{*}$ & 0.8 & $(-) 1.3-2.9$ & 0.44 & 0.5 & $(-) 0.6-1.6$ & 0.34 & $(-) 0.1$ & $(-) 1.2-1.0$ & 0.83 \\
\hline \multicolumn{16}{|l|}{ Age } \\
\hline Belgium & $(-) 0.01$ & $(-) 0.03-0.01$ & 0.25 & 0.01 & $(-) 0.003-0.03$ & 0.11 & $(-) 0.03$ & $(-) 0.05-0.0003$ & $0.05^{\star}$ & $(-) 0.01$ & $(-) 0.04-0.02$ & 0.59 & 0.03 & $(-) 0.01-0.06$ & 0.13 \\
\hline Chile & $(-) 0.03$ & $(-) 0.04-(-) 0.01$ & $<0.001^{*}$ & $(-) 0.01$ & $(-) 0.02-0.002$ & 0.09 & $(-) 0.09$ & $(-) 0.11-(-) 0.07$ & $<0.001^{*}$ & $(-) 0.04$ & $(-) 0.06-(-) 0.02$ & $<0.001^{*}$ & 0.02 & $(-) 0.01-0.05$ & 0.12 \\
\hline $\begin{array}{l}\text { Lateral } \\
\text { incisor }\end{array}$ & & & & & & & & & & & & & & & \\
\hline $\begin{array}{l}\text { Country } \\
\text { of origin }\end{array}$ & 0.7 & $0.2-1.1$ & $0.004^{*}$ & $(-) 0.6$ & $(-) 0.9-(-) 0.2$ & $0.002^{*}$ & 0.6 & $(-) 0.4-1.6$ & 0.22 & 0.6 & $(-) 0.003-1.2$ & 0.05 & 0.1 & $(-) 0.9-1.1$ & 0.82 \\
\hline \multicolumn{16}{|l|}{ Gender } \\
\hline Belgium & 0.9 & $0.3-1.5$ & $0.006^{*}$ & 0.5 & $0.02-1.1$ & $0.04^{*}$ & 0.2 & $(-) 0.7-1.1$ & 0.64 & 0.02 & $(-) 0.7-0.7$ & 0.95 & $(-) 0.5$ & $(-) 2.1-1.1$ & 0.55 \\
\hline Chile & 0.9 & $0.3-1.6$ & $0.005^{*}$ & 0.8 & $0.3-1.2$ & $0.003^{*}$ & 1.1 & $(-) 0.5-2.8$ & 0.16 & 0.9 & $(-) 0.1-1.9$ & 0.08 & $(-) 0.4$ & $(-) 1.5-0.7$ & 0.49 \\
\hline \multicolumn{16}{|l|}{ Age } \\
\hline Belgium & $(-) 0.004$ & $(-) 0.02-0.02$ & 0.69 & 0.01 & $(-) 0.003-0.03$ & 0.12 & $(-) 0.03$ & $(-) 0.05-(-) 0.007$ & $0.01^{\star}$ & $(-) 0.02$ & $(-) 0.03-0.001$ & 0.07 & 0.07 & $0.04-0.1$ & $<0.001^{*}$ \\
\hline Chile & $(-) 0.02$ & $(-) 0.04-(-) 0.01$ & $0.001^{*}$ & $(-) 0.005$ & $(-) 0.02-0.006$ & 0.36 & $(-) 0.04$ & $\begin{array}{c}(-) 0.07- \\
(-) 0.00002\end{array}$ & $0.05^{\star}$ & $(-) 0.02$ & $(-) 0.04-0.009$ & 0.22 & 0.03 & $0.01-0.06$ & $0.002^{\star}$ \\
\hline
\end{tabular}

number of canals, presence of a septum, and type of septum (Table 3). There were significant differences in root length and tooth length between the groups (Table 4). Age-related effects were found for tooth length in the Chilean sample, but no age-related effects were found for root length in either sample. Gender-related effects were found for tooth and root length in both samples. Age-related effects were also found for the distance between the intercanal septum to the incisal edge and for the distance between the intercanal septum and the apical foramen in mandibular lateral incisors, in both samples (Table 4).

\section{Discussion}

Periapical radiography is an essential tool for endodontic treatment. However, it has limitations such as a two-dimensional view of three-dimensional structure, revealing solely restricted aspects of the three-dimensional anatomy [27]. In distinction, CBCT is asophisticated diagnostic imaging technique that doesn't present geometrical distortion or anatomical noise; it provides threedimensional images of structures and permits accurate measurements of the information acquired [28]. This makes CBCT a useful tool for endodontic assessment, because it permits an in depth analysis of the anatomy before treatment.

It is possible that studies using CBCT for the study of root canal anatomy are hampered by limited resolution and slice thickness, in comparison with micro-CT [12], but the use of CBCT allows a method that is feasible and reproducible in an in vivo scenario, that's better than a periapical radiography. In an ex vivo study, micro-CT should be the chosen technique because it provides accuracy, high resolution and can be used for details measurement of the root canal anatomy [12].

Mandibular incisors can have sometimes complex root canal

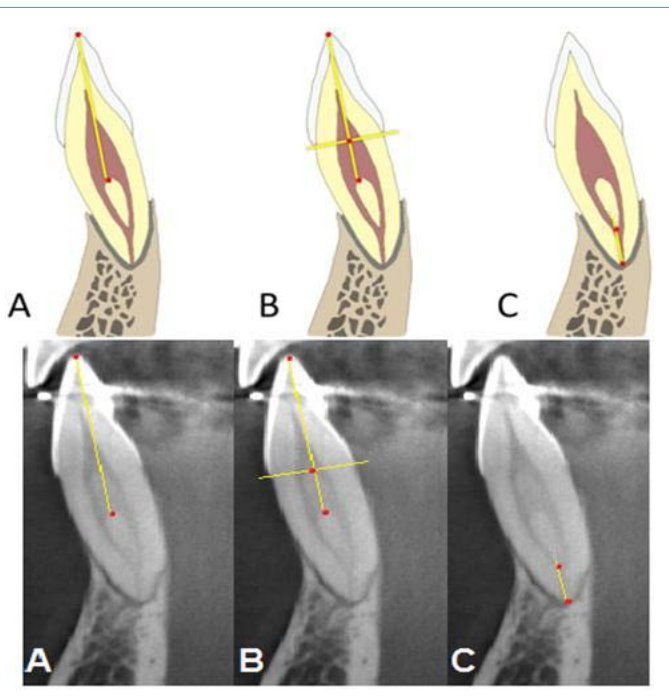

Figure 4: Measurements from the septum to different anatomical structures. A Measurement from the incisal border to the coronal limit of the septum. B Measurement from the cement-enamel junction (represented by the horizontal line) to the coronal limit of the septum. C Measurement from the apical limit of the septum to the root apex.

morphology. They can present multiple variations such as a second canal, apical delta, intercanal septum, and bifurcations, among others, which can become challenging during root canal treatment [2-6].

An inappropriate diagnosis of the anatomical configuration can lead to a series of complications and the failure of the endodontic treatment $[2,29]$. Therefore, it is critical to obtain a successful outcome, that professionals are informed about possible variations in these teeth before treating them. 
In this study, all CBCT images were obtained using the same scanner, from patients who required a CBCT examination as an integral part of their diagnosis and treatment planning. Standard protocol for acquiring images was not obtained because it varied on a case-by-case basis to ensure the lowest possible radiation dose. These variations may have compromised the collection of standardized images and the accuracy of the assessment. In future research, a standard image acquisition protocol should be defined, as far as possible, to ensure an optimal comparison.

The ethnic background was not taken into consideration as an inclusion criterion. Assessing specific ethnic groups may be challenging. Therefore, the individuals analyzed represent only a sample of the population attending the radiological centers in each country.

The literature has shown that the mandibular central incisor in most cases presents one root and one canal [7,10,26,30,31], corresponding with the results obtained in the present study. However, Sertand Bayirli published a study reporting a prevalence of one canal of only $32.5 \%$, which is not in line with the results obtained in this or any other published study [32]. That study used clearing and staining techniques to evaluate root canal morphology. The sample comprised 2800 maxillary and mandibular teeth from a Turkish population sample; 200 mandibular central incisors and 200 mandibular lateral incisors were evaluated.

The most common canal configurations in our study were Vertucci types I, III and II. The most prevalent in both samples was type I, followed by type III. In the Chilean simple, type I was present in $77.78 \%$ of the cases, while in the Belgian simple it was present in $61.49 \%$. Vertucci described a prevalence of $70 \%$ of type I cases (2), Han et al. reported a prevalence of $84.29 \%$ (10), while Zhengyanet al. found $96.24 \%$ in a Chinese sample [33].

The mandibular lateral incisor presented in this study with one root and one canal in most cases for both samples. Only one case with two roots was reported, in the Belgian sample; this rare variation has been described elsewhere in the literature [33]. A similar prevalence has also been reported by other authors $[2,4,32]$.

The prevalence of different root canal configurations of the mandibular lateral incisor was similar to that of the mandibular central incisor and is consistent with reports in the available literature, which classifies type I as the most prevalent $[1,4,29,32]$.

The curvature of the apical third of the canal is not commonly described in the literature. In this study, it was found that a curvature to the vestibular side was more prevalent in both central and lateral mandibular incisors, for both samples. This corresponds with the studies by Willershausenet al. [33] and Miyashita et al. [4]. There is no description available in the literature for the classification of the intracanal septum present in mandibular incisors. It is vital for a dentist to know the parameter of length in relation to the presence of a septum, to be prepared for the anatomical variations that may be present. The classification proposed in this study could be useful for future investigations to determine at what length the practitioner could expect to find the bifurcation of the canal or the joining of it, which is vital for treatment planning.
This investigation has shown that the prevalence of two canals is high, up to $47.06 \%$, therefore it is the responsibility of the dentist always to search for a second canal and be prepared for the possible configurations, of which type III is one of the most common.

Given that type III has a high prevalence in the mandibular incisor, the practitioner must be prepared for bifurcation and union of canals. The proposed classification of the intercanal septum and its relation to different anatomical structures tells the clinician when to expect bifurcation or unification. Furthermore, it indicates at what length to expect a second canal, giving critical information for root canal treatment. According to this investigation, professionals should expect bifurcation of the canals to occur between $11.69 \mathrm{~mm}$ and $12.25 \mathrm{~mm}$, taking the incisal edge as a reference, and can expect the unification of the canals to occur between $3.51 \mathrm{~mm}$ and $4.4 \mathrm{~mm}$ from the apical foramen. If a type II septum is diagnosed, it could disappear during mechanical preparation owing to its lack of definition and density, causing unification of the two canals.

This investigation also compared the nominal variables by gender and country of origin. The results show that the Belgian sample showed a greater likelihood of having two canals, an intercanal septum and atype II septum. When compared by gender, men in the Belgian sample had a greater risk of having two canals and an intercanal septum. This relationship was not statistically significant in the Chilean sample, but when comparing the type of intercanal septum with gender in the Chilean sample, women presented a greater likelihood of having type II and men type I.

For the quantitative variables, comparison was made by gender, country of origin, and age. The Belgian sample presented longer teeth, but for roots the Chilean sample showed a greater length. In both populations men had longer teeth and roots than women. Furthermore, an age-related effect was found for tooth length in the Chilean sample and for the distance from the intercanal septum to the in cisal border in both samples. This implies that as age increases the length, for both parameters, decreases.

\section{Conclusion}

The root canal morphology of 698 mandibular incisors was analyzed using CBCT in Chilean and Belgian samples. The mandibular central and lateral incisors presented more frequently with one root and one canal, in both samples. Types I, III and II canal configurations were most commonly found.

When comparing the characteristics of the mandibular incisor in the two sample groups, statistically significant differences were found for tooth length, radicular length, number of canals and the presence and type of intercanal septum. Furthermore, an age-related effect was found for tooth length in the Chilean sample, for the mandibular lateral and central incisors.

\section{Compliance with Ethical Standards \\ Human rights statements and informed consent}

All procedures followed were in accordance with the ethical standards of the responsible committee on human experimentation (institutional and national) and with the Helsinki Declaration of 1975 , as revised in 2008. Informed consent was obtained from all patients for being included in the study. 


\section{References}

1. Vertucci FJ. Root canal morphology and its relationship to endodontic procedures. Endod Top. 2005; 10: 3-29.

2. Vertucci FJ. Root canal anatomy of the mandibular anterior teeth. J Am Dent Assoc. 1974; 89: 369-371.

3. Funato $\mathrm{A}$, Funato $\mathrm{H}$, Matsumoto $\mathrm{K}$. Mandibular central incisor with two root canals. Dent Traumatol. 1998; 14: 285-286.

4. Miyashita M, Kasahara E, Yasuda E, Yamamoto A, Sekizawa T. Root canal system of the mandibular incisor. J Endod. 1997; 23: 479-484.

5. Al-Qudah AA, Awawdeh LA. Root canal morphology of mandibular incisors in a Jordanian population. Int Endod J. 2006; 39: 873-877.

6. Kabak YS, Abbott PV. Endodontic treatment of mandibular incisors with two root canals: Report of two cases. Aust Endod J. 2007; 33: 27-31.

7. Madeira MC, Hetem S. Incidence of bifurcations in mandibular incisors. Oral Surg Oral Med Oral Pathol. 1973; 36: 589-591.

8. Pineda F, Kuttler Y. Mesiodistal and buccolingual roentgenographic investigation of 7,275 root canals. Oral Surg Oral Med Oral Pathol. 1972 33: $101-110$.

9. Benjamin KA, Dowson J. Incidence of two root canals in human mandibular incisor teeth. Oral Surg Oral Med Oral Pathol. 1974; 38: 122-126.

10. Han $T$, Ma Y, Yang L, Chen X, Zhang X, Wang Y. A study of the root canal morphology of mandibular anterior teeth using cone-beam computed tomography in a Chinese subpopulation. J Endod. 2014; 40: 1309-1314.

11. Martins JNR, Marques D, Mata A, Caramês J. Root and root canal morphology of the permanent dentition in a Caucasian population: a conebeam computed tomography study. Int Endod J. 2017.

12. Ordinola-Zapata R, Bramante CM, Versiani MA, Moldauer BI, Topham G Gutmann JL, et al. Comparative accuracy of the Clearing Technique, CBCT and Micro-CT methods in studying the mesial root canal configuration of mandibular first molars. Int Endod J. 2017; 50: 90-96.

13. Rankine-Wilson RW, Henry P. The Bifurcated Root Canal in Lower Anterio Teeth. J Am Dent Assoc 1939. 1965; 70: 1162-1165.

14. Walker RT. Root form and canal anatomy of maxillary first premolars in a southern Chinese population. Endod Dent Traumatol. 1987; 3: 130-134.

15. Walker RT. Root form and canal anatomy of mandibular first molars in a southern Chinese population. Dent Traumatol. 1988; 4: 19-22.

16. Bellizzi R, Hartwell G. Clinical investigation of in vivo endodontically treated mandibular anterior teeth. J Endod. 1983; 9: 246-248.

17. Mauger MJ, Schindler WG, Walker WA. An evaluation of canal morphology at different levels of root resection in mandibular incisors. J Endod. 1998; 24 607-609.

18. Miyoshi S, Fujiwara J, Tsuji YH, Nakata T, Yamamoto K. Bifurcated Root Canals and Crown Diameter. J Dent Res. 1977; 56: 1425-1425.
19. Zhang R, Wang $\mathrm{H}$, Tian $\mathrm{Y}-\mathrm{Y}, \mathrm{Yu} \mathrm{X}, \mathrm{Hu} \mathrm{T}$, Dummer $\mathrm{PMH}$. Use of cone-beam computed tomography to evaluate root and canal morphology of mandibular molars in Chinese individuals. Int Endod J. 2011; 44: 990-999.

20. Zhang $\mathrm{R}$, Yang $\mathrm{H}$, Yu X, Wang $\mathrm{H}$, Hu T, Dummer PMH. Use of CBCT to identify the morphology of maxillary permanent molar teeth in a Chinese subpopulation. Int Endod J. 2011; 44: 162-169.

21. Cotton TP, Geisler TM, Holden DT, Schwartz SA, Schindler WG. Endodontic applications of cone-beam volumetric tomography. J Endod. 2007; 33: 11211132.

22. Pedemonte E, Cabrera C, Torres A, Jacobs R, Harnisch A, Ramírez V, et al. Root and canal morphology of mandibular premolars using cone-beam computed tomography in a Chilean and Belgian subpopulation: a crosssectional study. Oral Radiol. 2017; 3: 1-8.

23. Torres A, Jacobs R, Lambrechts P, Brizuela C, Cabrera C, Concha G, et al. Characterization of mandibular molar root and canal morphology using cone beam computed tomography and its variability in Belgian and Chilean population samples. Imaging Sci Dent. 2015; 45: 95-101.

24. Nolla C. The development of the permanent teeth. Journal of Dentistry for Children. 1960; 27: 254-266.

25. Gulabivala K, Aung TH, Alavi A, Ng YL. Root and canal morphology of Burmese mandibular molars. Int Endod J. 2001; 34: 359-370.

26. Vertucci FJ. Root canal anatomy of the human permanent teeth. Oral Surg Oral Med Oral Pathol. 1984; 58: 589-599.

27. Patel S, Dawood A, Ford TP, Whaites E. The potential applications of cone beam computed tomography in the management of endodontic problems. Int Endod J. 2007; 40: 818-830.

28. Scarfe WC, Farman AG, Sukovic P. Clinical applications of cone-beam computed tomography in dental practice. J Can Dent Assoc. 2006; 72: 75-80.

29. Arslan H, Ertas H, Ertas ET, Kalabalık F, Saygılı G, Capar ID. Evaluating root canal configuration of mandibular incisors with cone-beam computed tomography in a Turkish population. J Dent Sci. 2015; 10: 359-364.

30. Lin Z, Hu Q, Wang T, Ge J, Liu S, Zhu M, et al. Use of CBCT to investigate the root canal morphology of mandibular incisors. Surg Radiol Anat SRA. 2014; 36: 877-882.

31. Zhengyan Y, Keke L, Fei W, Yueheng L, Zhi Z. Cone-beam computed tomography study of the root and canal morphology of mandibular permanent anterior teeth in a Chongqing population. Ther Clin Risk Manag. 2015; 12 19-25.

32. Sert S, Bayirli GS. Evaluation of the Root Canal Configurations of the Mandibular and Maxillary Permanent Teeth by Gender in the Turkish Population. J Endod. 2004; 30: 391-398.

33. Willershausen B, Kasaj A, Röhrig B, Marroquin BB. Radiographic Investigation of Frequency and Location of Root Canal Curvatures in Human Mandibular Anterior Incisors In Vitro. J Endod. 2008; 34: 152-156.
Austin J Radiol - Volume 5 Issue 2 - 2018

ISSN : 2473-0637 | www.austinpublishinggroup.com

Brizuela et al. (C) All rights are reserved
Citation: Martínez I, Torres A, Jacobs R, Lepe A, Jara D, Ramírez V, et al. Root Canal Morphology of Mandibular Incisors Using Cone-Beam Computed Tomography in Two Population Samples: A Cross-Sectional Study. Austin J Radiol. 2018; 5(2): 1083. 